\title{
Political orientation and climate concern shape visual attention to climate change
}

\author{
Jennifer C. Whitman ${ }^{1,2}$, Jiaying Zhao ${ }^{1,3}$, Kevin H. Roberts ${ }^{1}, \&$ Rebecca M. Todd ${ }^{1}$ \\ ${ }^{1}$ Department of Psychology, University of British Columbia \\ ${ }^{2}$ Department of Psychology, Northwestern University \\ ${ }^{3}$ Institute for Resources, Environment and Sustainability, University of British Columbia
}

Acknowledgments. We thank Cassandra Bethel, Sumeyye Cakal, Hoiki Cheung, Bevan Lugg, Yu Luo, Joey Manaligod, Paniz Pasha, Rochelle Picardo, Emilie Ptak, Hwa Baek Song, Emily Suddes, Nicole Tsang, Aline Vilks, May Wang, Ru Qi Yu, and Michelle Zhang for their assistance with data collection and data management. This research was supported by NSERC Discovery grants to R. M. Todd (RGPIN-2014-04202) and to J. Zhao (RGPIN-2014-05617), the Leaders Opportunity Fund from the Canadian Foundation for Innovation to R. M. Todd (32102), by a Canadian Institutes for Health Research New Investigator Award to R. M. Todd, the Canada Research Chairs Program to J. Zhao, by a SSHRC Postdoctoral Fellowship (756-2016-0829) to J. C. Whitman, and by a SSHRC Insight Development Grant (430-2016-00031) awarded to R.M. Todd, J. Zhao, and J.C. Whitman.

\section{Corresponding Authors.}

1. Jennifer C. Whitman, PhD, jennifer.whitman@ northwestern.edu, Dept. Psychology, Northwestern University, 102 Swift Hall, 2029 Sheridan Rd, Evanston IL, 60208-2710

2. Jiaying Zhao, PhD, jiayingz@ psych.ubc.ca, Dept. Psychology \& Institute for Resources, Environment \& Sustainability, University of British Columbia

3. Rebecca M. Todd, PhD, becket.todd@psych.ubc.ca, Dept Psychology, University of British Columbia, 2136 West Mall, Vancouver BC Canada V6T 1Z4 


\begin{abstract}
Despite the scientific consensus, there is widespread public controversy about climate change. Previous explanations focused on interpretations hampered by political bias or insufficient knowledge of climate facts. We propose that public views of climate change may also be related to an attentional bias at a more basic level of cognitive processing. We hypothesized that selective visual attention toward or away from climate-related information would be associated with climate concern. To test prioritization of climate-related stimuli under conditions of limited attention, we asked participants to identify climate-related and neutral words within a rapid stream of stimuli. Undergraduate students attended to climate-related words more readily than neutral words. This attentional prioritization correlated with self-rated climate concern. We then examined this relationship in a more diverse community sample. Principal Component Analysis of survey data in the community sample revealed a component indexing a relationship between climate concern and political orientation. That component was correlated with the degree of selective inattention to climate-related words. Our findings suggest that climate-related communications may be most effective if tailored in a manner accounting for how attentional priorities differ between audiences - particularly those with different political orientations.
\end{abstract}

Keywords: Climate Change, Selective Attention, Political Orientation, Confirmation Bias, Communication, Attentional Blink 


\section{Introduction}

Despite the scientific consensus about anthropogenic climate change (Oreskes 2004), widespread public skepticism remains (e.g. Hornsey et al. 2016; Hulme 2009; Poortinga et al. 2011; Rainie et al. 2015; Weber and Stern 2011). One way to address this discrepancy is to tailor communications to improve public understanding (Lieserowitz 2007; Lorenzoni et al. 2007; Sheppard 2012). That improvement will be fundamental to achieving climate change mitigation and adaptation (Clayton et al. 2015). Previous accounts of the discrepancy between public understanding and the scientific consensus have focused on how interpretations can be biased by opposing political convictions (e.g. Giddens 2009; Lieserowitz 2006; McCright and Dunlap 2011; Rainie et al. 2015; Zhao et al. 2011) and hampered by insufficient knowledge about climate facts (Kahan et al. 2012; Lorenzoni et al. 2007).

We propose that public understanding of climate change may also be hampered by a more basic selective attentional process. Here we define attention as the visual prioritization of information in the environment. Visual selective attention is often described as enhancing the perception of relevant stimuli and filtering out competing information. In our account, attitudes about climate change are associated with attentional biases determining how likely an individual is to see climate-related information in the environment. For example, in a crowded visual scene such as a news website, the ability to notice climate-related words would be associated with an individual's level of existing concern about climate change.

To test our hypothesis, we examined whether existing concerns about climate change were associated with attention to climate-related information (e.g. words such as carbon). We measured attentional prioritization of climate-related words using an attentional blink (AB) task 
(Di Lollo et al. 2005; Raymond et al. 1992). The AB task measures attentional biases governing how a given visual stimulus is processed under conditions of high attentional demand. The 'blink' is a phenomenon in which people are unable to report the identity of a target stimulus if it is presented shortly after a previous target, with both targets embedded in a rapidly presented stream of distractor stimuli. After seeing the first target (T1), people typically fail to see the second target (T2), as if the mind blinks (for about $500 \mathrm{~ms}$ ).

Previous research has shown that when T2 is associated with emotional arousal or reward there is a consistently observed reduction in the attentional blink, or 'emotional sparing' (e.g. Anderson 2005; Huang et al. 2008; Keil and Ihssen 2004; Lee et al. 2013; Todd et al. 2013; Todd et al. 2014). The degree of sparing from the attentional blink can also reflect individual differences in prioritization of specific categories of stimuli (Lee et al. 2013; Todd et al. 2013). We thus hypothesized that individual differences in concern about climate change would be associated with sparing effects for climate-related information.

In this paper, we first examined whether climate-related words were prioritized within a student sample at a university where there is a strong emphasis on sustainability and awareness of climate change. In Experiment 1 we found an overall pattern of climate word sparing in undergraduate students. The degree to which the sparing was observed was correlated with reported concerns about climate change. In Experiment 2 we examined whether performance on the $\mathrm{AB}$ task was associated with demographic measures in a larger sample from the general public in British Columbia. Here, principal component analysis revealed a component indexing concerns about climate change and political orientation. Liberal politics and greater concern were associated with overall higher accuracy in reporting climate-related target words. A pattern 
of "climate change blindness" reflecting poorer accuracy for climate-related words at early lags was strongest in conservatives with low concern. The results collectively demonstrate that the people concerned about climate change attend to climate-related information most readily, at the level of rapid visual processing.

\section{Results}

\subsection{Experiment 1: Attention correlates with climate concerns.}

To test attentional prioritization of information about climate change, we analyzed the accuracy with which target words were reported in an attentional blink (AB) task. The sequence of events for each trial in this task is portrayed in Fig. 1a. Embedded in each stream of rapidly presented distractor words, the first target (T1) was always a repeating digit. The second target (T2) was either a word related to climate change or a neutral word. After the AB task, participants rated each target word for intensity of emotional arousal and for semantic relatedness to climate change. In a sample of UBC undergraduate students, we examined attentional blink effects for Climate-Related and Neutral words, and assessed whether a pattern of $\mathrm{AB}$ sparing for Climate-Related words was related to individual differences in climate concern. Specifically, we tested whether those more concerned about climate change showed a stronger AB sparing effect for Climate-Related words (relative to Neutral words).

Climate-Related words were rated as significantly more climate-related, $t(94)=21.82$, $p<.001$, and significantly more arousing, $t(94)=14.42, p<.001$, than Neutral words. In order to ascertain whether undergraduates demonstrated $\mathrm{AB}$ sparing for Climate-Related words, accuracy scores for all conditions were analyzed using a two-way repeated-measures ANOVA with Word 
a)

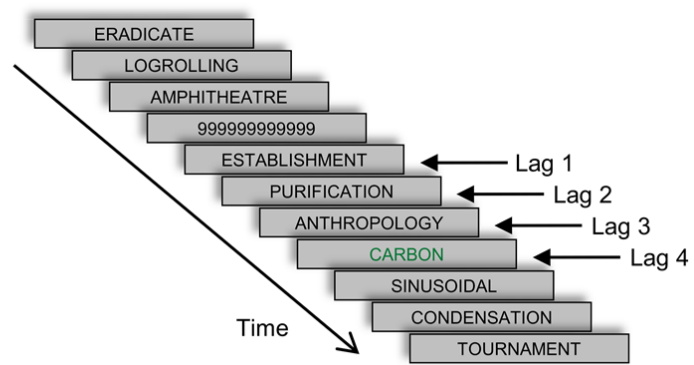

b)

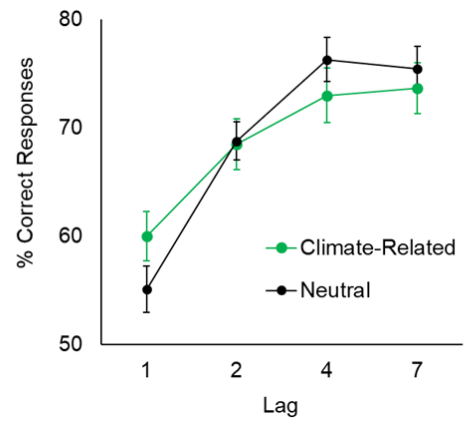

Fig. 1. a) Attentional blink (AB) task. After each rapid stream of stimuli, participants reported both the first and second targets (T1 and T2). T1 was always a string of repeating digits. T2, presented in green, was either a neutral word or a climate-related word. b). Participants in Experiment 1 reported Climate-Related words more accurately than Neutral words at Lag 1 but not at late Lags. Error bars represent one standard error of the mean.

Category (Climate-Related vs. Neutral), and $\operatorname{Lag}(1,2,4$, and 7) as within-subject factors. The dependent variable was the accuracy with which the identities of T2 targets were reported on trials where T1 targets were also correctly reported. All pairwise contrasts were Bonferroni corrected to control for multiple comparisons.

Results revealed a significant main effect of $\operatorname{Lag}, F(3,282)=53.02, p<.001, \eta^{2}=0.36$, with accuracy increasing at later lags. There was no significant main effect of Word Category averaged across lags, $p=.91$. Typically differences in AB effects between conditions are indicated by an interaction between Lag and Word Category, with differences observed at Early Lags (MacLean and Arnell 2012). Crucially, we observed an interaction between Word Category and Lag, $F(3,282)=5.20, p=.002, \eta^{2}=0.05$, as can be seen in Fig. 1b. AB effects are typically reported at either Lag 1 or 2, as the lag at which the $\mathrm{AB}$ is greatest depends on the stimulus onset asynchrony used, the type of stimuli used, and individual processing speed (Di Lollo et al. 2005). In young adults, when T2 belongs to a separate category from T1 (e.g., digits vs. words) the greatest blink effect is observed at Lag 1 (Di Lollo et al. 2005). We observed the greatest blink effects at Lag 1 in our previous research (Todd et al. 2013; Todd et al. 2014), and in the current 
study (see Fig. 1b). Planned contrasts showed higher Lag 1 accuracy for Climate-Related words than Neutral words, $p=.005$. This demonstrates that at Lag 1 , where the $\mathrm{AB}$ was most pronounced, the participants were literally more likely to see words associated with climate change. Importantly, the difference in Lag 1 accuracy between conditions (Climate-Related > Neutral) was correlated with self-rated levels of concern about climate change, $r(95)=.24, p=.02$. The variability in AB sparing at Lag1 is depicted in a histogram in Supplemental Fig. S1. This supports our hypothesis that concerns about climate change are linked to prioritized attention to Climate-Related information.

\subsection{Experiment 2: Political orientation and climate concerns prioritize attention.}

In Experiment 1, we found $\mathrm{AB}$ sparing for climate words in an undergraduate sample. Importantly, we observed a relationship between climate concerns and the degree of $\mathrm{AB}$ sparing, measured as the difference in Lag 1 accuracy between Climate-Related and Neutral words. However, if we wish to draw conclusions about the broader implications of these individual differences in $\mathrm{AB}$ effects, we must examine how they relate to individual differences between members of a larger and more diverse demographic group.

Thus, the primary goal of Experiment 2 was to examine variables related to individual differences in the selective attention for or against climate related information. More specifically, we explored a range of sociocultural, situational, and demographic measures that might be associated with climate concerns (Kahan et al. 2012; McCright and Dunlap 2011; Milfont et al. 2012; Rainie et al. 2015). Each participant in Experiment 2 completed a survey reporting their age, gender, income, profession, cultural background, religion, preferred news sources, and experience with natural disasters. They also independently rated their level of approval of several 
Canadian political parties, their degree of concern about the environment, and their perception of the probability that climate change would have negative impacts in their local geographical area, in wider geographical areas, in the near and distant future. We also calculated how much each participant's self-reported level of concern (Likert scale rating) varied as a function of geographical distance by using linear regression to calculate a slope for each participant. We performed an analogous regression for temporal distance. A list of fifty-two key questions is provided in the Supplementary Material. Additional questions answered by a subset of participants are in survey code available at https://figshare.com/s/92cc8f300459c6bfc8de, along with data files and code used for stimulus presentation. Prior to the survey, each participant performed the attentional blink task. $\mathrm{AB}$ effects have been consistently found to be delayed with age (for a review, see Willems et al. 2016). Thus, to examine individual differences while adjusting for the wider age range in the general public, we binned accuracy scores into Early (Lags 1 and 2) and Late (Lags 4 and 7) lags within each word category.

We used the survey data to conduct an exploratory investigation of measures associated with climate concerns. To assess the associations between responses to different survey questions, we used Principal Component Analysis. This allowed us to identify the dominant pattern(s) in the survey data in an unbiased, data-driven manner. Our primary goal was to identify the patterns of intercorrelations between measures, rather than to identify how much variance was attributable to each measure. One principal component (PC 1) clearly emerged as the strongest pattern in the data upon visual inspection of the scree plot (see Supplementary Fig. S2). It accounted for $8.5 \%$ of the variance while the remaining PCs each accounted for less than 4\%. The strongest loadings for PC 1 are depicted in Fig. 2. The strongest positive loadings included eight slightly different judgments of the likelihood of negative consequences from 


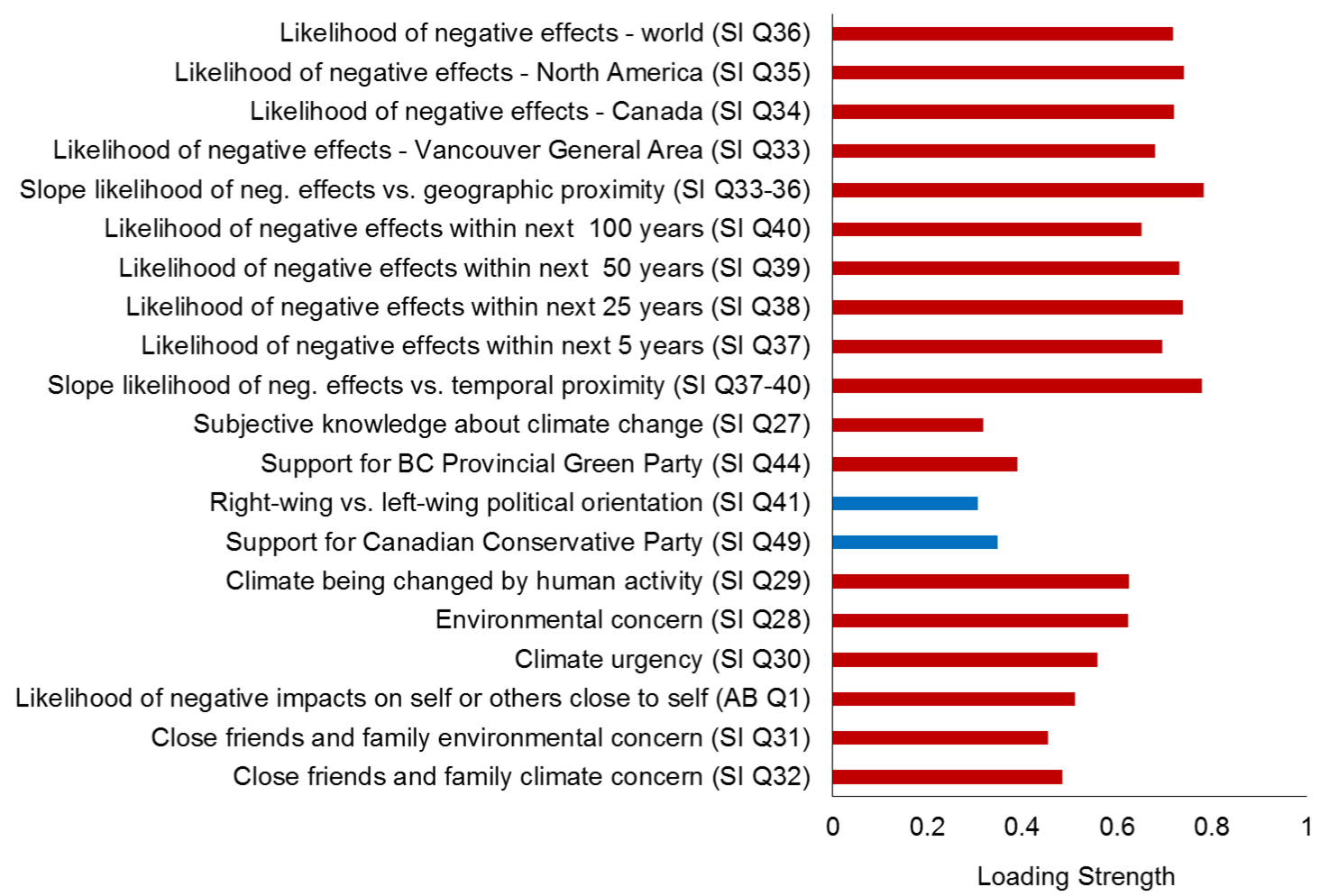

Fig. 2. Positive (red) and negative (blue) loadings from the principal component analysis of questionnaire responses in Experiment 2. The questions with the strongest $20 \%$ of loadings are depicted. Question numbers refer to those listed in the Supplementary Materials. Positive scores on this component correlated with attentional prioritization of climate-related words.

climate change. The strongest negative loadings were for right-wing political orientation and support for the Conservative Party of Canada. Based on Study 1 and our previous research (e.g. Todd et al. 2013; Todd et al. 2014), we hypothesized that the difference in Early Lag accuracy for Climate-Related relative to Neutral words would be associated with this component. Individual scores on PC 1 correlated significantly with differences between Word Categories in accuracy at Early Lags, $r(578)=.19, p<.001$. This reflected a pattern of "climate change blindness" in those with conservative political orientations and low climate concerns, involving reduced Early Lag accuracy for Climate-Related relative to Neutral words. In other words, those 
less concerned about climate change were selectively inattentive to Climate-Related information. We have also included correlations between all survey variables and $\mathrm{AB}$ sparing effect at Early Lags - see Supplementary Table S1. Additional correlations between survey variables are available in the spreadsheet at https://figshare.com/s/9ff3587724cb8faf799c).

To more thoroughly investigate the relationship between PC1 and attentional blink sparing, we performed a median split on $\mathrm{PC} 1$ and conducted a $2 \times 2 \times 2$ repeated measures ANOVA with Word Category (Climate-Related vs. Neutral) and Lag (Early vs. Late) as withinsubjects factors, and Group (Concerned Liberal vs. Unconcerned Conservative) as a betweensubjects factor. All pairwise contrasts were Bonferroni corrected for multiple comparisons. Results revealed a main effect of $\mathrm{Lag}, F(1,576)=913.77, p<.001, \eta^{2}=.61$, with higher accuracy at Late Lags. There was also a main effect of Word Category $F(1,576)=7.77, p=.005, \eta^{2}=.01$, with overall higher accuracy for Climate-Related words. There was no significant main effect of Group, $F(1,576)=0.12, p=.73, \eta^{2}=.00$.

There was a significant Word Category $\times$ Group interaction, $F(1,576)=10.34, p=.001$, $\eta^{2}=.02$ (see Figure 3a). Across all lags, the Liberal Concerned group showed greater accuracy for Climate-Related than Neutral words, $p<.001$. In contrast, the Conservative Unconcerned group showed no difference in accuracy between Word Categories, $p=.763$. Thus, in addition to correlational differences related to $\mathrm{PC} 1$ at early lags, the Liberal Concerned group was more highly tuned to Climate-Related words across Lags. Results also indicated a Lag $\times$ Group interaction, $F(1,576)=7.46, p=.006, \eta^{2}=.01$. This reflected a pattern of higher accuracy for the Conservative Unconcerned group at Early Lags and the Liberal Concerned group at Late Lags; however, pairwise comparisons revealed these contrasts to be non-significant, $p \mathrm{~s}>.1$. There was 
also a Word Category $\times$ Lag interaction, $F(1,576)=219.97, p<.001, \eta^{2}=.28$ (Figure $\left.3 b\right)$.

Pairwise comparisons showed overall greater accuracy for Climate-Related words at Late Lags, and vice versa at Early Lags $(p s<.005)$.

a)

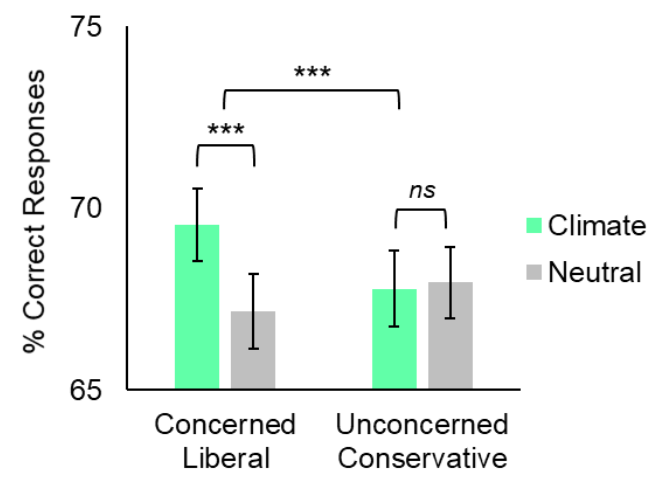

c)

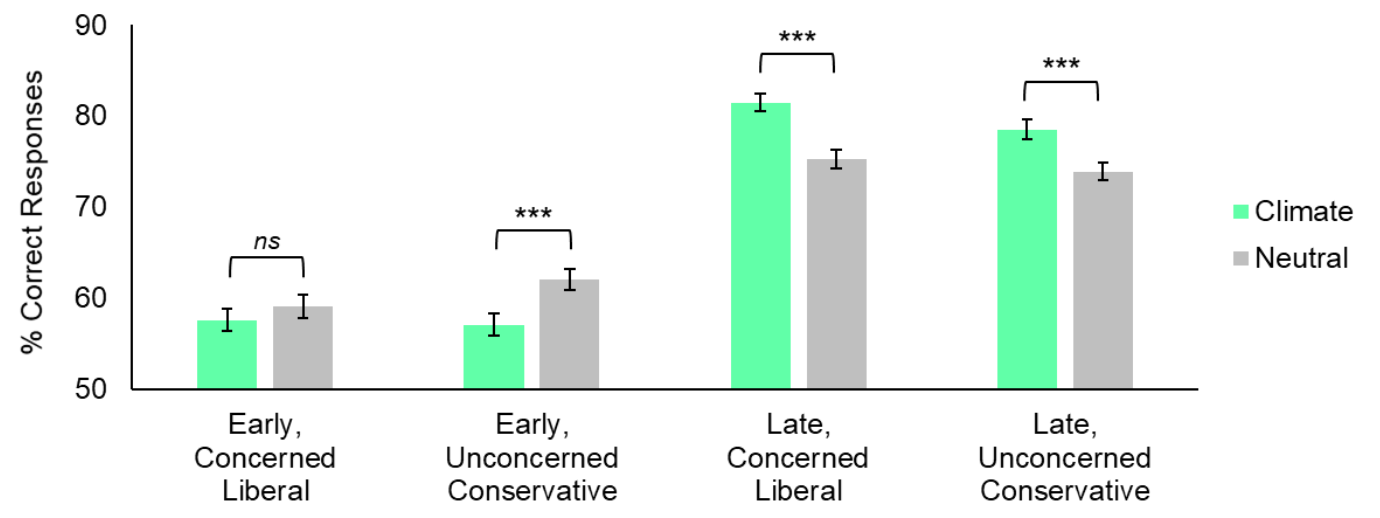

Fig 3. Estimated marginal means from ANOVAs reported for Experiment 2. a) Group $\times$ Word Category. b) Lag $\times$ Word Category. c) Group $\times \operatorname{Lag} \times$ Word Category $(* p<.05, * * p<.01$, *** $p<.001)$. 
There was no significant 3-way interaction of Word Category $\times \operatorname{Lag} \times$ Group, $F(1,576)=$ $2.57, p=.11, \eta^{2}=.00$. However, to allow for a clearer interpretation of the findings reported above, the mean values for each cell in this design are depicted in Figure 3c. At Early Lags, the Unconcerned Conservative group was less accurate for Climate-Related words than for Neutral words, $p<.001$. The smaller difference in the same direction for the Concerned Liberal group did not reach significance, $p=.053$. Thus, whereas neither group in this population showed the climate word sparing effect observed in undergraduates, a pattern of relative climate word blindness at Early Lags was more pronounced in the Conservative Unconcerned group. On a continuous scale, it was variation in this early $\mathrm{AB}$ difference between word conditions that was linked to scores on the Principal Component indexing political orientation and concern about climate change. To summarize, the Liberal Concerned group showed greater overall accuracy for Climate-Related words while the Conservative Unconcerned group showed no difference. At Early Lags, where the $\mathrm{AB}$ is evident, Unconcerned Conservatives showed a pronounced $\mathrm{AB}$ effect for Climate-Related relative to Neutral words, consistent with a pattern of "climate change blindness".

Of course, a median split is rather arbitrary cutoff for categorizing people's political orientations and levels of concern. The correlational analysis reported initially better captures the gradation of individual differences. Moreover, $40 \%$ of participants exhibited higher accuracy for Climate-Related words than for Neutral words at Early Lags. The variability in AB sparing at early Lags is depicted in a histogram in Supplemental Fig. S3. 


\section{Discussion: Attentional prioritization of information about climate change}

In this paper, we examined whether attentional biases associated with the likelihood of perceiving climate-related information are associated with existing concerns about climate change. We first examined this within an undergraduate sample at a university where there is a strong emphasis on sustainability and climate change awareness (Experiment 1). We found that climate words were given more attentional priority than neutral words. This was evident in sparing from the attentional blink - an effect where identification of target words presented within a stream of rapidly presented distractors is impaired (e.g. Anderson 2005; Huang et al. 2008; Tibboel et al. 2011; Todd et al. 2013; Todd et al. 2014). Importantly, the AB sparing for climate words was correlated with the self-rated strength of concerns about climate change. Participants also rated the climate-related words as more emotionally arousing than the neutral words. As emotionally arousing words also elicit blink sparing (Anderson 2005; Todd et al. 2013), the effect we observe may be due in part to the emotional salience of the climate-related words. Future research may examine further the relationship between the emotional salience of climate-related stimuli and climate concern.

In a larger community sample (Experiment 2), the early lag accuracy difference between climate and neutral words was correlated with a principal component indexing the negative relationship between concerns about climate change and conservative political orientation. At early lags, unconcerned conservatives showed higher accuracy for neutral words than for climate words, suggesting selective inattention to climate-related cues. Moreover, although it does not reflect selective attention effects indexed by the $\mathrm{AB}$ per se, the liberal and concerned group showed overall greater accuracy for climate related words while the conservative unconcerned group did not. This suggests that the relationship between explicit concern and attention to 
climate cues extends beyond effects of rapid selective attention and includes persistent prioritization of climate-relevant cues when attentional resources are less constrained. These findings support our hypothesis that levels of concern about climate change are linked to attentional prioritization of climate-related information. By focusing on the principal component representing the dominant pattern in the survey data, we optimized our analysis for testing whether individual differences reflected in the survey responses were associated with the visual attentional priority given to climate-related words in the attentional blink task. Now that this association has been established, future research may explore its precise nature in more detail, assessing how much each individual measure contributes to the relationship.

The finding that individual differences in concern are associated with attention to climate-related information has important implications. It indicates that prior beliefs and concerns are associated with how individuals orient to information in the environment, selectively prioritizing or filtering evidence of climate change. This attentional prioritization could ultimately give rise to confirmation bias favoring new information expected to support existing opinions (Nickerson 1998). Our current findings point to another promising direction for future research, which is to design interventions to increase visual attention to climate-related information among climate deniers.

The current findings have important implications for climate-related communications. For example, future communication strategies should consider how best to draw the attention of people who are unconcerned or in denial. One approach might be to pair climate-related information with terms linked to other politically polarized issues likely to draw the attention of climate deniers. Certainly, we should tailor our climate-related communications in a manner accounting for how attentional priorities vary with political orientation. Such manipulations 
might be effective if we employ moral framings appealing to those with right-wing politics (appealing to values such as purity, patriotism, and obedience to authority (Wolsko et al. 2016). Another potential avenue is to tailor climate communication with the message that climate actions can lead to a more considerate and caring society and greater economic/technological development (Bain et al., 2012). The optimal strategy would simultaneously address both barriers to attention and biases involving interpretational frameworks. Such adjustments will be fundamental to boosting public understanding, and, in turn, boosting efforts towards mitigation and adaptation. 


\section{Methods}

Ethics approval for all experiments reported here was obtained from the UBC Behavioural Research Ethics Board. All participants provided written informed consent.

\subsubsection{Code Availability.}

The code for all tasks and surveys is available at https://figshare.com/s/92cc8f300459c6bfc8de.

\subsection{Experiment 1}

\subsubsection{Participants}

Ninety-five UBC undergraduates (mean age 20.7 years, sixty-nine females) participated for course credit. As a rule of thumb, we consider $N=80$ to be a minimum sample size for any study using correlational analyses to test for individual differences. A more detailed discussion of statistical power and rationale for sample sizes, for both Experiments 1 and 2, can be found in the Supplementary Material.

\subsubsection{Procedure}

Participants first performed an attentional blink task. On each trial, participants viewed (see Fig. 1a), a stream of stimuli presented in rapid succession. SOAs ranged from $116 \mathrm{~ms}$ to 183 $\mathrm{ms}$ in $16.6 \mathrm{~ms}$ increments, depending on individual performance in the practice session. They then reported the identities of two targets: a string of repeating digits (T1) and a word in green font (T2). T2 was either Climate-Related or Neutral. Full lists of each type of target word are included in the Supplemental Materials. As in previous work (Todd et al. 2013; Todd et al. 
2014), target word categories were matched in terms of word length, English language frequency, and neighbourhood frequency, to ensure that neither simple familiarity nor visual characteristics of the words drove any differences in findings between target word types. The assignment of individual target words to different Lags was randomized across participants.

T1 was randomly placed $3^{\text {rd }}, 4^{\text {th }}, 5^{\text {th }}$, or $6^{\text {th }}$ in the rapid serial visual presentation (RSVP) stream. There were four T1-T2 Lags: T2 either immediately followed T1 (Lag 1) or followed it after 1, 3, or 6 intervening distractors (Lags 2, 4, and 7, respectively). The number of distractors following T2 was kept constant across trials, so that they were equated in terms of working memory load. Participants completed 56 trials for each of the two target word types, for a total of 112 trials.

Task timing was individually calibrated to minimize performance differences stemming from individual differences in perceptual processing speed. During the practice session we presented 30 trials with proper names used as targets, at five different SOAs, ranging from 116 to $183 \mathrm{~ms}$ in $16.6 \mathrm{~ms}$ increments. We added $16.6 \mathrm{~ms}$ to the fastest SOA for which participants reported $\mathrm{T} 2$ with greater than $80 \%$ accuracy at $\operatorname{Lag} 7$, then used that value as the SOA for all items in the subsequent main experiment.

Following the attentional blink and word rating tasks, participants also responded to the question 'How concerned are you about climate change?' by using a mouse to move a cursor along a Likert scale with the following labels, arranged with equal spacing: 'Not at all concerned', 'Somewhat concerned', 'Very concerned', and 'Extremely concerned'. Participants also rated each target word for how emotionally arousing it was (intensity regardless of positive or negative valence). 


\subsection{Experiment 2}

\subsubsection{Participants}

$N=578$ participants were recruited from the general public (mean age 34.1 years, $S D=$ 15.5 years, 315 women, 261 men, 2 reporting their gender as 'other') and reimbursed $\$ 10$ per hour. $N=442$ participants were recruited and tested (on laptop computers) at shopping malls in several municipalities adjacent to Vancouver, BC, Canada, spanning a range of urban and suburban areas. $N=56$ participants were recruited and tested in a mall in Kamloops, BC, where the economy relies strongly on consumption of natural resources and there is a history of electing more conservative political representatives than in Vancouver. The remaining participants were recruited within community centres, libraries, public parks, and the UBC campus. The sample of $N=578$ participants was in keeping with a rule of thumb where we consider $N=500$ to be a bare minimum for identifying individual differences in a community sample and in a study with multiple predictors (which we expected to be more independent from each other a priori), and with the fact that a minimum sample size of $N=354$ is necessary for detecting a population correlation of $\rho=.19$ (the observed correlation from Experiment 1). A more detailed discussion of statistical power and rationale for sample sizes, for both Experiments 1 and 2, can be found in the Supplementary Material.

\subsubsection{Procedure}

The procedures were identical to those of Experiment 1 (e.g. same number of trials, same words used as targets, etc...) with the following exceptions: SOAs ranged from 116 to $250 \mathrm{~ms}$ in $33.5 \mathrm{~ms}$ increments, depending on individual performance in the practice session. This wider range of SOAs was optimized for the increased variability in age, visual acuity, and processing 
speed in the community sample (relative to the undergraduate sample). The assignment of individual target words to different Lags was not randomized across participants. This ensured that any between-subjects comparisons, within a given Lag and word category (i.e. Lag 1, climate-related) could not be confounded with features such as word length or written frequency, because the same target words were used for each participant within a given Lag (and word category).

For the sake of expedient data collection in a community setting, we included no word ratings. There was one question about climate concern incorporated as part of the code for the attentional blink task. It asked "How likely is it that climate change will have a negative effect on you personally or someone close to you? Please enter 1-7 and press the <ENTER> key". Following completion of the $\mathrm{AB}$ task, participants also completed the survey described in the results section and the Supplementary Material. Some participants completed longer forms of the survey. Missing values were replaced by the mean for that variable prior to analysis. All PCA results depict the unrotated solution, from Matlab's SVD function. 


\section{References}

Anderson AK (2005) Affective influences on the attentional dynamics supporting awareness $\mathbf{J}$ Exp Psychol Gen 134:258-281

Clayton S et al. (2015) Psychological research and global climate change. Nat Clim Change 5:640-646

Di Lollo V, Kawahara J, Shahab Ghorashi SM, Enns JT (2005) The attentional blink: resource depletion or temporary loss of control? Psychological research 69:191-200

Giddens A (2009) The politics of climate change. Cambridge, UK

Hornsey MJ, Harris EA, Bain PG, Fielding KS (2016) Meta-analyses of the determinants and outcomes of belief in climate change. Nat Clim Change 6:622-626

Huang YM, Baddeley A, Young AW (2008) Attentional capture by emotional stimuli is modulated by semantic processing J Exp Psychol Human 34:328-339

Hulme M (2009) Why we disagree about climate change: Understanding controversy, inaction and opportunity. Cambridge University Press,

Kahan DM, Peters E, Wittlin M, Slovic P, Ouellette LL, Braman D, Mandel G (2012) The polarizing impact of science literacy and numeracy on perceived climate change risks Nat Clim Change 2:732-735

Keil A, Ihssen N (2004) Identification facilitation for emotionally arousing verbs during the attentional blink Emotion 4:23-35

Lee D, Todd RM, Gardhouse K, Levine B, Anderson AK (2013) Enhanced attentional capture in survivors of a single traumatic event. . Paper presented at the Annual Meeting of the Society for Neuroscience, San Diego, CA, 
Lieserowitz A (2006) Climate change risk perception and policy preferences: The role of affect, imagery, and values. Climatic Change 77:45-72

Lieserowitz A (2007) Communicating the risks of global warming: American risk perceptions, affective images, and interpretive communities. In: Creating a climate for change: Communicating climate change and facilitating social change. pp 44-63

Lorenzoni I, Nicholson-Cole S, Whitmarsh L (2007) Barriers perceived to engaging with climate change among the UK public and their policy implications Global Environ Chang $17: 445-459$

MacLean MH, Arnell KM (2012) A conceptual and methodological framework for measuring and modulating the attentional blink Atten Percept Psycho 74:1080-1097

McCright AM, Dunlap RE (2011) The politicization of climate change and polarization in the American public's views of global warming, 2001-2010 Sociol Quart 52:155-194

Milfont TL, Harre N, Sibley CG, Duckitt J (2012) The Climate-Change Dilemma: Examining the Association Between Parental Status and Political Party Support J Appl Soc Psychol 42:2386-2410

Nickerson RS (1998) Confirmation bias: A ubiquitous phenomenon in many guises. Review of General Psychology 2

Oreskes N (2004) Beyond the ivory tower - The scientific consensus on climate change Science 306:1686-1686

Poortinga W, Spence A, Whitmarsh L, Capstick S, Pidgeon NF (2011) Uncertain climate: An investigation into public scepticism about anthropogenic climate change Global Environ Chang 21:1015-1024 
Rainie L et al. (2015) Americans, politics, and science issues. Pew Research Center, Washington, D.C.

Raymond JE, Shapiro KL, Arnell KM (1992) Temporary suppression of visual processing in an RSVP task: An attentional blink? Journal of experimental psychology Human perception and performance 18:849-860

Sheppard SRJ (2012) Visualizing climate change: a guide to visual communication of climate change and developing local solutions. Routledge, Oxon, UK

Tibboel H, De Houwer J, Spruyt A, Crombez G (2011) The attentional blink is diminished for targets that form coherent semantic categories Acta Psychologica 136:321-328

Todd RM et al. (2013) Genes for emotion-enhanced remembering are linked to enhanced perceiving Psychol Sci 24:2244-2253

Todd RM et al. (2014) Temporal-spatial neural activation patterns linked to perceptual encoding of emotional salience Plos One 9

Weber EU, Stern PC (2011) Public Understanding of Climate Change in the United States Am Psychol 66:315-328

Willems C, Saija JD, Akyürek EG, Martens S (2016) An individual differences approach to temporal integration and order reversals in the attentional blink task Plos One 11

Wolsko C, Ariceaga H, Seiden J (2016) Red, white, and blue enough to be green: Effects of moral framing on climate change attitudes and conservation behaviors Journal of Experimental Social Psychology 65:7-19

Zhao XQ, Leiserowitz AA, Maibach EW, Roser-Renouf C (2011) Attention to science/environment news positively predicts and attention to political news negatively predicts global warming risk perceptions and policy support J Commun 61:713-731 


\section{Author Attribution}

R. M. T. conceived the study with J. Z. R. M. T., J. C. W., J. Z., \& K. H. R. contributed to study design, J. C. W. analyzed the data and wrote the paper with R. M. T \& J. Z. 


\section{Compliance with Ethical Standards}

There are no potential conflicts of interest to disclose. Ethical review was conducted by the University of British Columbia Behavioural Research Ethics Board. All participants provided written informed consent prior to participation. 


\title{
Supplementary Material
}

Political orientation and climate concern shape attention to climate change

\author{
Jennifer C. Whitman ${ }^{1,2}$, Jiaying Zhao ${ }^{1.3}$, Kevin H. Roberts ${ }^{1}$, \& Rebecca M. Todd ${ }^{1}$ \\ ${ }^{1}$ Department of Psychology, University of British Columbia \\ ${ }^{2}$ Department of Psychology, Northwestern University \\ ${ }^{3}$ Institute for Resources, Environment and Sustainability, University of British Columbia
}

Corresponding Author. Please address all correspondence to Jennifer C. Whitman, PhD, Department of Psychology at Northwestern University, 102 Swift Hall, 2029 Sheridan Rd, Evanston IL USA, 60208-2710, e-mail: jennifer.whitman@ northwestern.edu. 
List of Climate-Related Words Used as Targets: gasoline, oil, storm, extreme, resources, hurricane, melting, global, flooding, $\mathrm{CO} 2$, carbon, warming, climate, drilling, habitats, ozone, typhoon, drought, footprint, pollution, dioxide, wildfire, rainstorm, glacier, emissions, depletion, hydrocarbon, earth.

List of Neutral Words Used as Targets: collection, equivalent, decorate, calculator, direction, container, machinery, intuition, geography, bookshelf, shop, paint, download, optional, overalls, tutelage, bottle, hammer, pencil, sleeve, mixing, kettle, packet, puddle, lower, cable, upper, lock.

Note. Each target word appeared twice in the full experiment, with the ordering of trials randomized. This allowed for 56 trials from each word category. 
Supplemental Fig. S1. Histogram depicting how participants in Experiment 1 vary in the magnitude of $A B$ sparing at $\operatorname{Lag} 1$. A positive value on the $x$-axis represents $A B$ sparing for Climate-Related words, while a negative value represents suppression of Climate-Related information, relative to Neutral words.

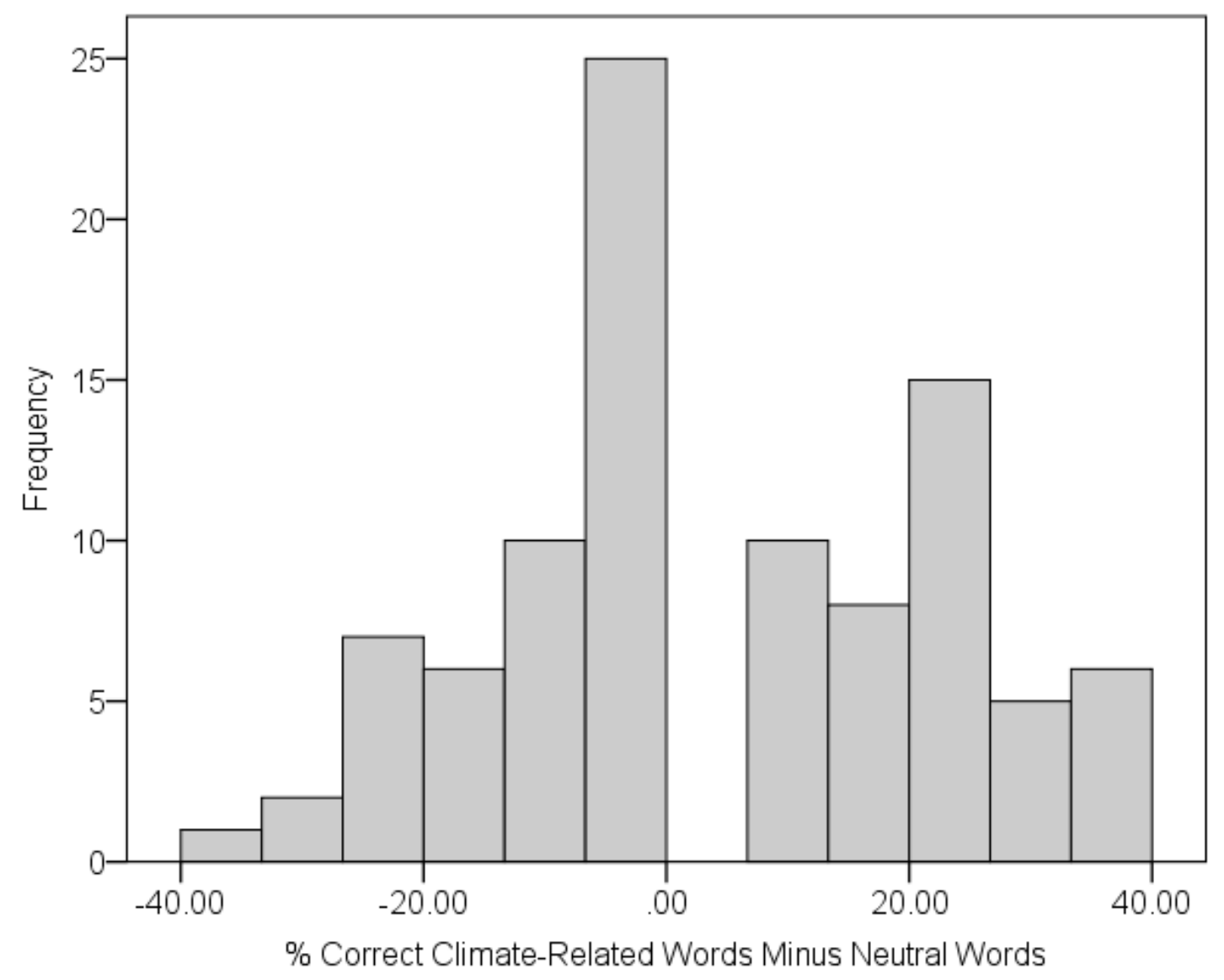


Supplementary Fig. S2. Scree Plot from Principal Component Analysis in Experiment 2

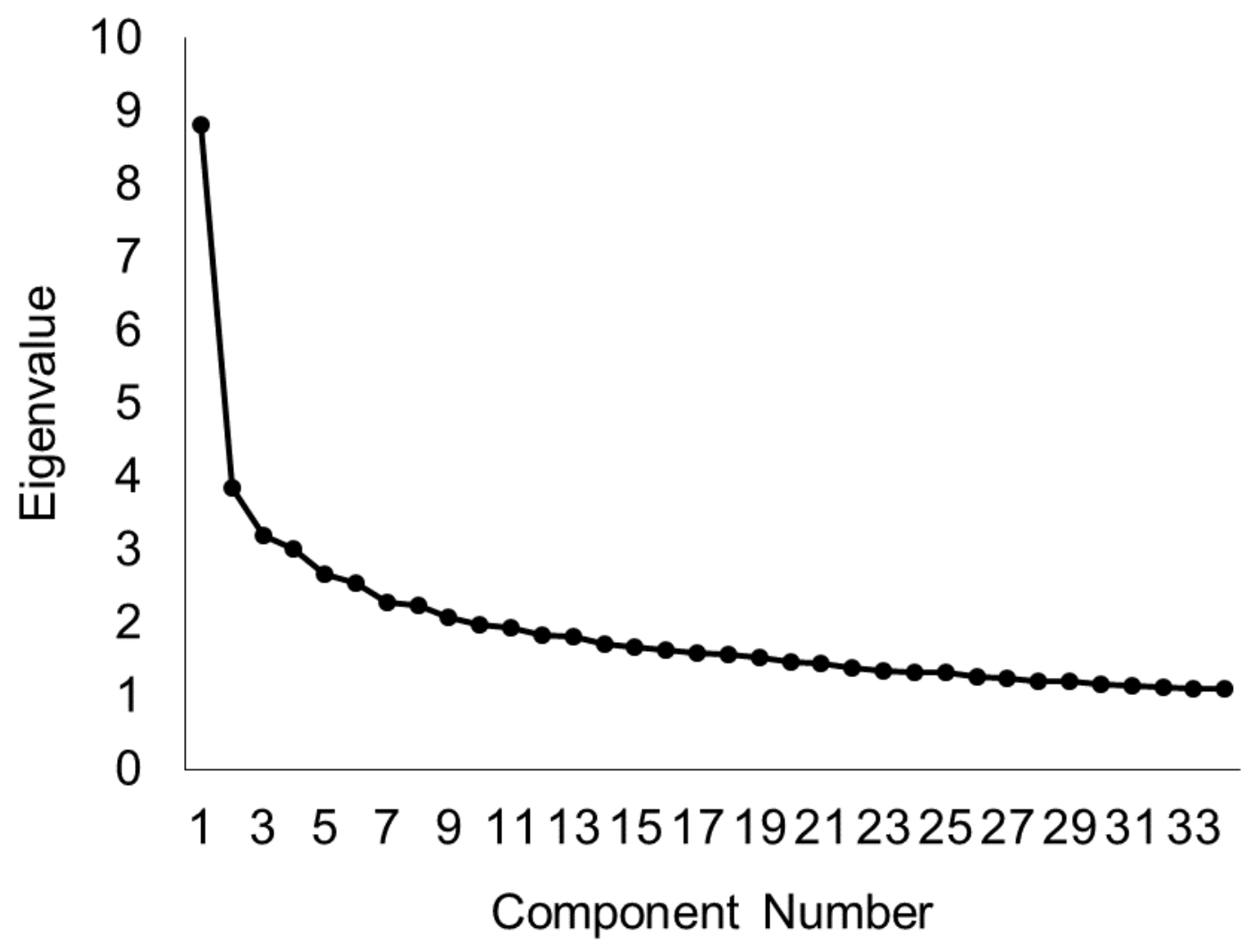


Supplemental Fig. S3. Histogram depicting how participants in Experiment 2 vary in the magnitude of $\mathrm{AB}$ sparing. A positive value on the $\mathrm{x}$-axis represents $\mathrm{AB}$ sparing for ClimateRelated words, while a negative value represents suppression of Climate-Related information, relative to Neutral words.

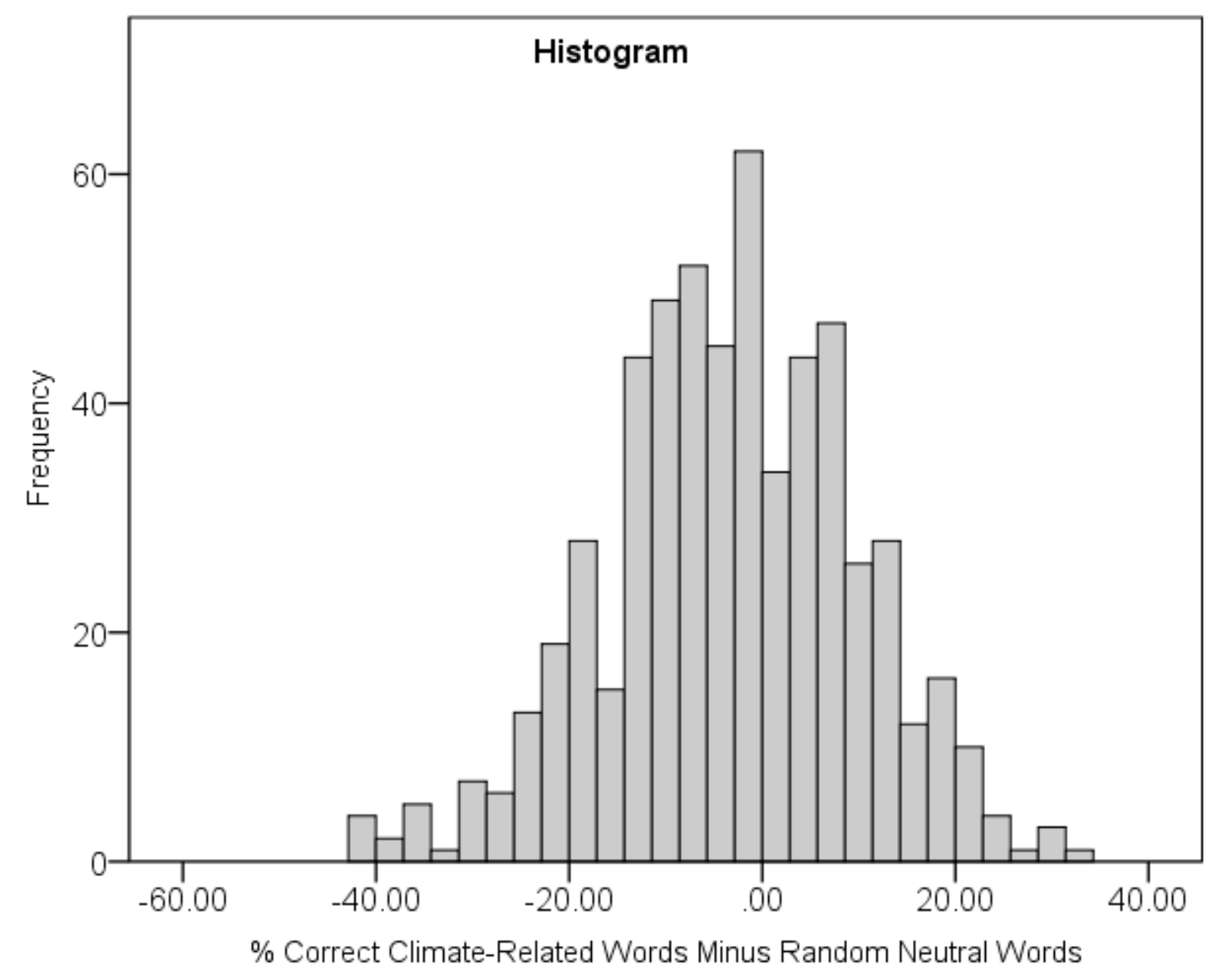




\section{Rationale for Samples Sizes and Analyses of Statistical Power in Experiments 1 and 2}

In planning and running Experiment 1, we aimed to schedule $N=100$ participants, based on a rule of thumb, employed by social psychologists, that $N=80$ participants is a bare minimum for any correlational analysis of individual differences. $N=95$ of our participants kept their appointments and participated in the Experiment. We considered $N=500$ to be a bare minimum for identifying individual differences in a community sample, with wider variability in age, education level, health, intelligence, visual acuity, and reading speed in a study with multiple predictors. At the time of the study design, we had expected to identify multiple orthogonal principal components each accounting for substantial portions of the variance in the survey data, rather than the single dominant principal component identified in our results (see Fig. S2). These general rules of thumb consider not only statistical power, discussed in more detail below, but also the consideration that a sample should be large enough to have a reasonable chance of being representative of the population about which inferences are made. Thus, our rules of thumb prescribe larger samples for the more diverse populations in the general community.

Here, using G-Power software, we report a series of [post-hoc] power analyses to examine the sample sizes we would need to detect different sizes of population effects at the $p<$ .05 level (two-tailed). This is in keeping with an approach suggested by O'Keefe (O'Keefe 2007). Detecting a population correlation of $\rho=.10$ would require a sample of at least $N=1293$. For a population correlation of $\rho=.20$, we would require a sample of at least $N=319$; for a population correlation of $\rho=.30$, a sample of at least $N=138$; for a population correlation of $\rho=$ .40 , a sample of at least $N=75$; and, for a population correlation of $\rho=.50$ we would require a sample of at least $N=46$. 
Based on the observed correlation of $r=.19$ in Experiment 1, we conducted a power analysis which suggested that a sample of $N=354$ would be necessary to detect the effect in Experiment 2 (assuming a population correlation of $\rho=.19$ ). This indicates that our sample of $N$ $=578$ in Experiment 2 was adequate. 
Supplemental Table S1. Correlations between survey variables and AB sparing at Early Lags.

Criterion Variable from Survey
Correlation $p$ -

Coefficient $r$ value

Human Caused (Supplemental Material Q 29)

$.030 \quad .466$

Climate Urgency (Supplemental Material Q 30)

$.012 \quad .771$

Climate Effects Vancouver Gen Area (Supplemental Material Q 33)

$.123^{* *} \quad .003$

Climate Effects Canada (Supplemental Material Q 34)

$.189^{* *} \quad .000$

Climate Effects Continent (Supplemental Material Q 35)

$.164^{* *} \quad .000$

Climate Effects World (Supplemental Material Q 36)

$.204^{* *} \quad .000$

Slope Climate Effects Geog. (slope from SM Q 33 to 36 above)

$.193^{* *} \quad .000$

Climate Effects 5years (Supplemental Material Q 37)

$.056 \quad .179$

Climate Effects 25years (Supplemental Material Q 38)

$.120^{* *} \quad .004$

Climate Effects 50years (Supplemental Material Q 39)

$.127^{* *} \quad .002$

Climate Effects 100years (Supplemental Material Q 40)

$.160^{* *} \quad .000$

Slope Climate Effects Time (calculated from above questions)

$.162^{* *} \quad .000$ 
$* p<.05$, uncorrected

$* * \mathrm{p}<.01$, uncorrected

Note that the 'Politics Self Left vs. Right (Supplemental Material Q 41)' variable has lower variance, relative to support for the 'CDN Conservative' party, due to a programming error on the first version of the survey made in psychoPy, which made it necessary to exclude that question for $N=119$ participants. These missing values were replaced by the mean from the remaining participants. Left vs. Right-wing political orientation did correlate strongly with several questions indexing environmental concern, as can be seen in the Supplementary spreadsheet CorrCoefoutputs for Supplemtary Materials.xlsx, posted on figshare at https://figshare.com/s/9ff3587724cb8faf799c 


\section{List of key survey questions in Experiment 2}

1. Please specify your gender (gender identity even if different from biological sex).

Male / Female / Other - please specify

2. Please specify your age.

3. What country do you live in?

Canada / Other - please specify

4. What city do you live in?

5. What languages can you speak fluently?

6. How long have you been in the Vancouver General Area?

I'm just visiting / I've lived here less than a month / I've lived here less than a year / I've lived here more than a year / I've lived here more than 5 years / I've lived here more than 10 years

7. What is your approximate annual income (before taxes)?

8. What is your current occupation?

9. Which of the following jobs or industries have you worked in?

retail / food service / tourism / forestry / mining / oil or natural gas / education / health / transportation / shipping / film or animation / programming or IT / midlevel management, general office admin or clerical / Other - please specify

10. What is the highest level of schooling you've completed? 
some highschool / completed highschool / 1 year post-secondary / 2 years postsecondary / Bachelor's degree / Master's degree / [Ph.D./M.D./J.D./LL.D.]

11. What is the highest level of schooling you've completed in math or statistics?

grade 10 / grade 11 / grade 12 / 1st year college/university / 2nd year college/university / 3rd year university / 4th year university / graduate school course

12. Please list several cities/towns you've lived in that have had an effect on who you are (minimum of one place).

13. What is the longest time you've spent living in one town or city?

less than 5 years / between 5 and 10 years / between 10 and 20 years / more than 20 years

14. Please list any terms you feel describe your nationality, heritage, and culture. Be specific. Some examples include:

Chinese Canadian, family mostly from Canton province \& Hong Kong African American

Canadian, probably mostly European ancestors

half Scottish, half Japanese 
15. Do you have a religion?

Yes / No

[If yes] 15b. : What is your religion?

[If yes] 15c. How often do you participate in activities with your religious community, such as going to a church/mosque/synagogue/temple?

not applicable - no religion / less than once a year / a few times a year / almost every week / more than once a week

16. Do you have children?

Yes / No

[If yes] 16b. How old are your children?

17. Do you have grandchildren?

Yes / No

[If yes] 17b. Please specify the age of your youngest grandchild.

18. Do you own property?

Yes / No

[If yes] 18b. Please specify the location(s) of your property (or properties) by naming the nearest intersection(s).

[coded for vertical distance from sea level. No street addresses recorded, in order to protect confidentiality]

[If yes] 18c. Do you plan to sell your property soon?

never; it'll be inherited / probably someday / in the next few years / as soon as possible 
19. Please list your favourite news sources (e.g. CNN, The Province, etc...).

20. Does your job require you to work outdoors?

never / rarely / sometimes / almost always

21. Are you Canadian, planning to become Canadian, or planning to live a long time in Canada?

Yes / No

22. Do you enjoy debating political issues?

not at all, never / somewhat, sometimes / yes, very much

\section{Likert Scale Questions}

23.

Are you interested in politics?

$\begin{array}{ccccc}\text { not at all: } & \text { not very } & \text { somewhat } & \text { very } & \text { extremely } \\ \text { I don't care } & \text { interested } & \text { interested } & \text { interested } & \text { interested }\end{array}$

24. Politically, would you describe your close friends and family as

$\begin{array}{ccccc}\text { very } & \text { somewhat } & \text { evenly } & \text { somewhat } & \begin{array}{c}\text { very } \\ \text { left-wing }\end{array} \\ \text { left-wing } & \text { mixed } & \text { right-wing } & \text { right-wing } \\ \text { on average } & \text { on average } & & \text { on average } & \text { on average }\end{array}$

25. Do you consider yourself an independent thinker?

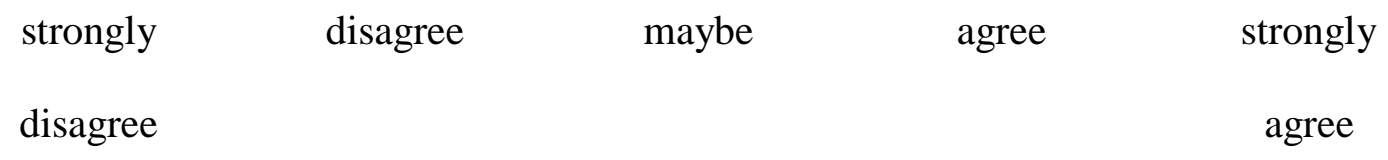


26. Do you tend to be an anxious person?
strongly
disagree
maybe
agree
strongly
disagree
agree

27. How well-informed are you about climate change?

I know almost I know a little bit I'm somewhat I'm very well- I'm an expert nothing about about it well-informed informed

it

28. How concerned are you about the environment in general?

$\begin{array}{ccccc}\text { not at all } & \text { a tiny bit } & \text { somewhat } & \text { very concerned } & \text { extremely } \\ \text { concerned } & \text { concerned } & \text { concerned } & & \text { concerned }\end{array}$

29. Do believe that the climate is being changed by human activity (i.e. carbon emissions)?

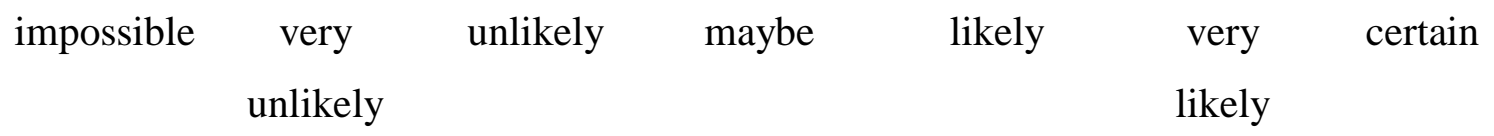

30. Do you think climate change will get harder to prevent or slow down the longer we wait to deal with it?
strongly
disagree
don't know
agree
strongly
disagree
agree

31. How concerned are your close friends and family about the environment in general?

$\begin{array}{ccccc}\text { not at all } & \text { a tiny bit } & \text { somewhat } & \text { very concerned } & \text { extremely } \\ \text { concerned } & \text { concerned } & \text { concerned } & & \text { concerned }\end{array}$


32. How concerned are your close friends and family about climate change?

$\begin{array}{ccccc}\text { not at all } & \text { a tiny bit } & \text { somewhat } & \text { very concerned } & \text { extremely } \\ \text { concerned } & \text { concerned } & \text { concerned } & & \text { concerned }\end{array}$

33. How likely is it that people in the Vancouver General Area and Fraser Valley will be negatively affected by climate change?

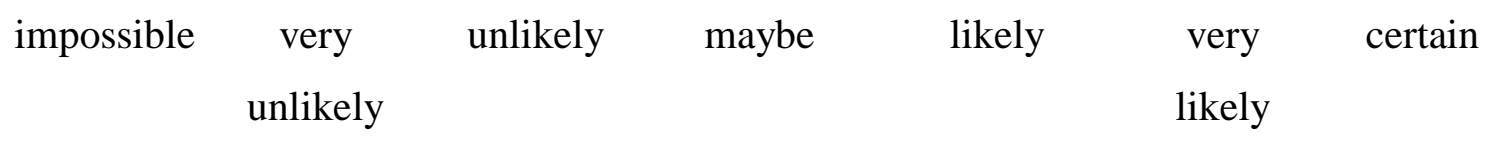

34. How likely is it that people in Canada will be negatively affected by climate change?

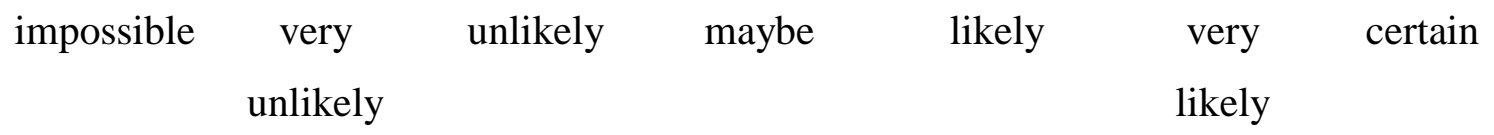

35. How likely is it that people on this continent will be negatively affected by climate change?

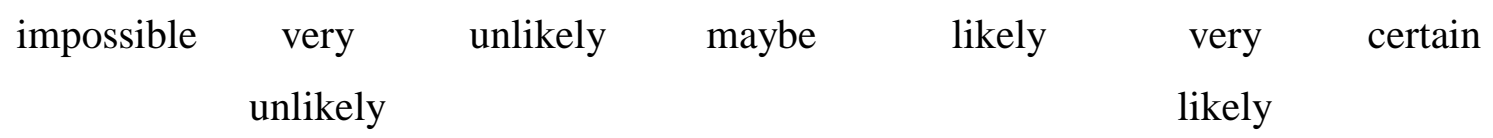

36. How likely is it that people anywhere in the world will be negatively affected by climate change?

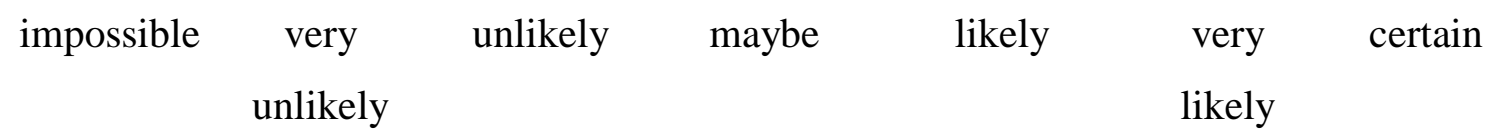


37. How likely is it that people will be negatively affected by climate change in the next 5 years?

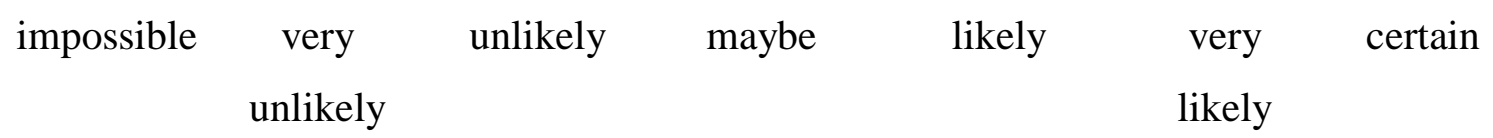

38. How likely is it that people will be negatively affected by climate change in the next 25 years?

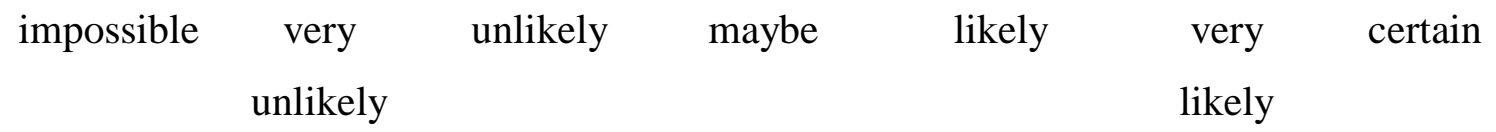

39. How likely is it that people will be negatively affected by climate change in the next 50 years?

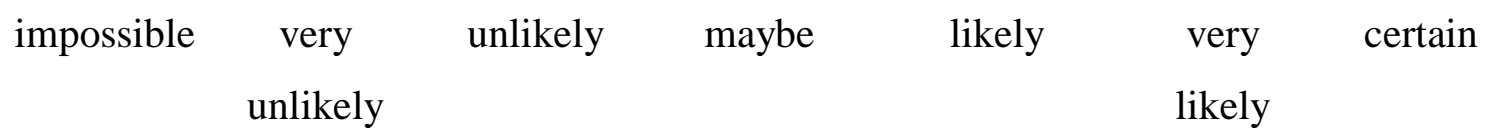

40. How likely is it that people will be negatively affected by climate change in the next 100 years?

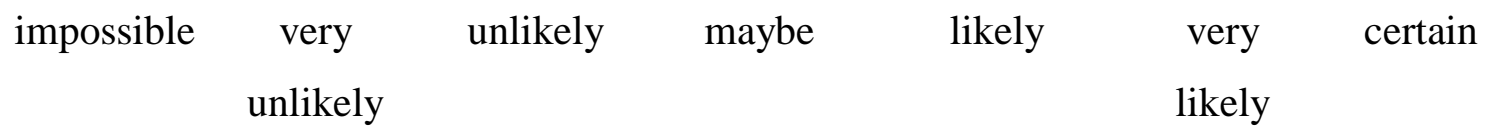

41. Politically, would you describe yourself as left-wing or right-wing?

$\begin{array}{cccccc}\text { far left socialist } & \text { New } & \text { Liberal } & \text { Conservative } & \text { USA } & \text { far right } \\ & \text { Democratic } & \text { Party of } & \text { Party of } & \text { Tea } & \\ & \text { Party of } & \text { Canada } & \text { Canada } & \text { Party } & \\ \text { Canada } & & & & \end{array}$


If you didn't have to choose only one party to vote for in BC PROVINCIAL elections, and instead you could support and rate several parties at once, how would you rate each of these parties?"

42.

Liberal Party of BC

$\begin{array}{llccr}\text { strongly } & \text { mildly } & \text { neutral } & \text { mildly } & \text { strongly } \\ \text { oppose } & \text { oppose } & & \text { support } & \text { support }\end{array}$

43.

New Democratic Party of BC

strongly

mildly

neutral

mildly

strongly

oppose

oppose

support

support

44.

Green Party of BC

strongly

mildly

neutral

mildly

strongly

oppose

oppose

support

support

45.

Social Credit Party (formerly) of BC

strongly

mildly

neutral

mildly

strongly

oppose

oppose

support

support 
If you didn't have to choose only one party to vote for in CANADIAN FEDERAL elections, and instead you could support and rate several parties at once, how would you rate each of these parties?"

46. Liberal Party of Canada

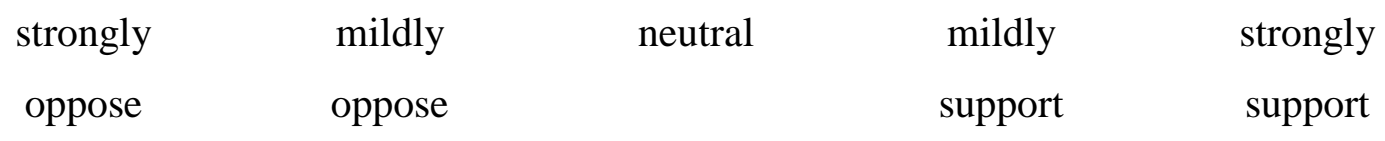

47.

New Democratic Party of Canada

\begin{tabular}{|c|c|c|c|}
\hline $\begin{array}{l}\text { strongly } \\
\text { oppose }\end{array}$ & $\begin{array}{l}\text { mildly } \\
\text { oppose }\end{array}$ & neutral & $\begin{array}{l}\text { mildly } \\
\text { support }\end{array}$ \\
\hline
\end{tabular}

48.

Green Party of Canada

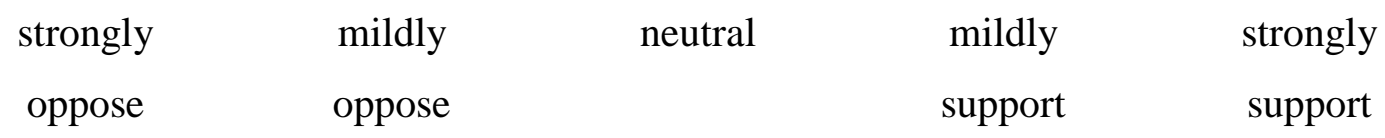

49.

Conservative Party of Canada

strongly

mildly

neutral

mildly

strongly

oppose

oppose

support

support 


\section{Questions with Check-box Options}

50. Have you been personally affected by a natural disaster (e.g. forest fire, mud/land slide, flood, storm surge)?

$$
\text { Yes / No }
$$

[If yes] 36b. Which natural disaster(s) have personally affected you? Please check all that apply.

forest fire / mud slide / land slide / river flood / ocean flood, e.g. storm surge

51. Have any of your close friends or family members been affected by a natural disaster (e.g. forest fire, mud/land slide, flood, storm surge)?

Yes / No

[If yes] 37b. Which natural disaster(s) have affected your close friends or family members? Please check all that apply.

forest fire / mud slide / land slide / river flood / ocean flood, e.g. storm surge

52. Have any members of your community been affected by a natural disaster (eg.. forest fire, mud/land slide, flood, storm surge)?

Yes / No

[If yes] 38b. Which natural disaster(s) have affected your community? Please check all that apply.

forest fire / mud slide / land slide / river flood / ocean flood, e.g. storm surge 


\section{Supplemental References}

O'Keefe DJ (2007) Brief report: post hoc power, observed power, a priori power, retrospective power, prospective power, achieved power: sorting out appropriate uses of statistical power analyses. Communication methods and measures 1:291-299 